\title{
Mulheres trabalhando em seringais acreanos (1960/1980)
}

Aldemira Ferreira de Almeida ${ }^{1}$

A trajetória do trabalho feminino retratando a mulher como trabalhadora cumpridora de deveres e obrigações ao longo de muitas décadas é um fato que permanece destituído de reconhecimento por boa parte das autoridades, dos empregadores e até mesmo de familiares. É comum ouvir-se dizer quando a mãe ou esposa não tem uma remuneração, que ela não trabalha, pois o marido é que leva dinheiro para casa. É como se todo o trabalho do lar não tivesse valor.

Na região norte do Brasil, mais precisamente no Estado do Acre, entre os anos 1960 a 1980, a situação não era muito diferente das demais regiões brasileiras. O trabalho exaustivo também era comum para grande parte das trabalhadoras acreanas, principalmente nos longínquos seringais da extensa floresta que embeleza tão vasta região.

A condição social vivida por mulheres seringueiras chama a atenção sobre o modo natural de se ver o envolvimento de mulheres em trabalhos ou funções delimitadas como especificamente masculinas. É uma condição discriminatória de divisão sexual do trabalho que, de certa forma, foi aos poucos sendo absorvida pelas próprias mulheres brasileiras que permaneceram por longo período caladas, submetendo-se a incontáveis situações constrangedoras e desumanas pelas quais passavam com frequência em seus locais de trabalho.

1 Mestranda em História pelo Programa de Pós Graduação em História da Universidade Federal do Amazonas - PPGH/UFAM 
As inúmeras atividades exercidas pelas mulheres no mundo das florestas dos seringais denotam a eficácia e a influência que as mesmas exerciam sobre seus familiares, bem como a responsabilidade que Ihes era atribuída. A pesquisa executada através de fontes orais dá a essas mulheres a possibilidade de serem ouvidas e de exporem suas experiências nas lutas, na dura lida trabalhista e, principalmente, na dificuldade de reconhecimento. Conforme Rua (2000), a ausência de reconhecimento dos trabalhos desenvolvidos pelas mulheres faz parte das relações de gênero.

É desse modo que entendemos história social. Neste sentido, inte-
ressam ao investigar as lutas reais; não só aquelas que se expres-
sam sob formas organizadas (sindicatos, partidos, associações vá-
rias) como também as "formas surdas" de resistência, estratégias
ocultas de subordinação e controle (VIEIRA, 2005: 18).

Com o advento da Segunda Guerra mundial, vários acordos foram assinados entre o Brasil e os Estados Unidos, conhecidos como os Acordos de Washington ${ }^{2}$. O governo brasileiro convocou mais de 50 mil homens para o serviço militar com o intuito de encaminhá-los para a região norte. Assim, alistaram-se como soldados alguns ainda solteiros e boa parte casados. Para os casados havia a promessa de que, após sua estabilização no novo local, suas famílias também se dirigiriam para lá. No nordeste, grande parte das mulheres permaneceu sem nunca mais ter notícias de seus maridos.

De acordo com Simonian (2001), que aborda o trabalho de mulheres seringueiras na Amazônia brasileira, a persistência de uma ideologia sexista faz com que esse trabalho duro seja encarado como trabaIho de homem, contribuindo para que, assim, a atuação das mulheres nessa atividade seja silenciada.

Diversas mulheres que se integraram ao chamado junto aos maridos permaneceram nos seringais. Algumas, por doenças ou pela idade elevada, já morreram, mas os fatos ocorridos ainda permeiam

2 Acordos de Washington: o governo norte americano passaria a investir na produção de borracha amazônica e o governo brasileiro encaminharia trabalhadores para os seringais. 
a memória de seus descendentes. Inúmeras famílias acreanas formaram-se a partir desse novo contingente migratório de soldados, pois boa parte dos que vieram solteiros constituíram suas famílias nos seringais. E dessas famílias é que descendem as trabalhadoras aqui mencionadas.

Os governos dos Estados amazônicos interessados organizaram serviços de propaganda e concederam subsídios para gastos de transporte. Formou-se, assim, a grande corrente migratória que fez possível a expansão da produção de borracha na região amazônica, permitindo à economia mundial preparar-se para uma solução definitiva do problema (FURTADO, 1970: 133).

Segundo Albuquerque (2005), que relata o cotidiano dos trabalhadores do Muru, a vida nos seringais e a construção da sobrevivência era uma luta diária experimentada pelas famílias. A sensação de abandono em locais isolados, a dificuldade de alimento ou mesmo de direitos os direcionava a adaptarem-se da melhor maneira possível.

Essas práticas, experimentadas por grupos de trabalhadores e consolidadas em espaços localizados, sinalizavam não apenas uma constante diversidade das atividades desses sujeitos, mas conflitos que conduzem à afirmação de novas identidades, à proporção que alteram suas relações com a natureza, expressão típica de suas culturas (ALBUQUERQUE, 2005: 115).

Com o término da guerra, o esquecimento por parte do governo foi vivenciado pelas famílias que trabalhavam nos seringais e a adaptação a novos recursos foi surgindo aos poucos. Um exemplo disso é o cultivo de castanha, muito comum nos seringais, assim como a plantação de alimentos de primeira necessidade. Como relata Albuquerque,

Se a jornada do corte da seringa propicia um isolamento do indivíduo em relação à família, mesmo quando corta em companhia dos filhos, a derrubada e queimada de áreas para o roçado, o plantio, limpezas e outras atividades vinculadas à agricultura de subsistência, implicam uma socialização do trabalho com a par- 
ticipação esporádica de vizinhos e, constantemente, de todo o núcleo familiar: esposa e filhos (ALBUQUERQUE, 2005: 111).

Muitos seringueiros ou soldados da borracha ${ }^{3}$ não puderam voltar às suas terras de origem pelo fato de nunca terem sido pagos pelos seringalistas que os contrataram, visto que alguns desses seringalistas faleceram e outros faliram fechando assim os seus seringais que pouco produziam, além, é claro, do baixíssimo preço a que eram obrigados a negociar o produto.

As mulheres, com seus companheiros ou sozinhas, continuaram no exercício da fabricação da borracha através do processo de defumação por um longo período, ainda que em baixa escala. Estas eram vendidas por um preço consideravelmente baixo.

Trabalhando de sol a sol nas estradas cortando seringa, defumando a borracha e cuidando dos afazeres de suas casas, assim foram se acostumando com a dura vida nos seringais. Muitos homens morreram por conta das dificuldades encontradas no interior da floresta amazônica, alguns por doenças, como a malária, outros por picadas de cobras venenosas, e atacados por onças, jacarés e outros animais.

Isso torna perceptível que o trabalho feminino nos seringais foi de vital importância. É possível assemelhar as formas de trabalho e lutas dessas mulheres seringueiras, com o analisado por Sader (1995) em relação aos acontecimentos ocorridos na vida de trabalhadoras da cidade de São Paulo, o que refletiu na consciência de seus direitos e obrigações por serem responsáveis pelo sustento ou por parte dele na família.

A consciência de seus direitos consiste exatamente em encarar as privações da vida privada como injustiças no lugar de repetições naturais do cotidiano. E justamente a "revolução" de expectativas produzida por essas mulheres esteve na busca de uma valorização da sua dignidade, não mais no estrito cumprimento de seus papeis tradicionais, mas sim na participação co-

3 Soldados da borracha é o nome pelo qual ficaram conhecidos os nordestinos que atenderam ao chamado do governo para trabalhar nos seringais amazônicos. 
letiva numa luta contra os que consideraram as injustiças de que eram vítimas (SADER, 1995: 222)

A mulher seringueira também se fez presente em ocasiões especiais, inclusive em lutas armadas de enfrentamento. Um exemplo disso é a situação conhecida como empate ${ }^{4}$. Seus familiares vieram para a região mediante um contrato de trabalho assinado pelo governo federal, contudo, foram deixados à mercê do tempo, esquecidos.

Em uma série de entrevistas com mulheres seringueiras, foi possível constatar algumas experiências vivenciadas. Levando em conta que as entrevistas se efetivaram dentro do que se entende por história oral e memória, são necessários alguns esclarecimentos sobre este procedimento em que o objeto de estudo do pesquisador ou historiador é recuperado através de memórias daqueles que se dispõem a recuperar o tempo ou período que ainda permanece tão presente. Segundo Amado (2000), "[n]a história oral, existe a geração de documentos (entrevistas) que possuem uma característica singular: são resultado do diálogo entre sujeito e objeto de estudo".

A recuperação da memória em função da pesquisa estabelece uma importância primordial. O relato torna-se documento e expõe a realidade vivenciada por pessoas que sobreviveram a situações de absoluta dificuldade no âmbito trabalhista e social. Segundo Silva,

A memória é marcada, portanto, por dimensões de invenção, seleção e combinação temáticas no social, que se diferenciam do passivo acúmulo, deixando patentes caracteres de disputa em sua definição (2003:68).

Durante longo período inúmeras mulheres permaneceram trabaIhando silenciosamente nos mais longínquos seringais da região amazônica e foram, por muitos, esquecidas. Em seringais da Amazônia Acreana, os acontecimentos vividos por essas mulheres foram intensos, sem reconhecimento, perigosos e, de certa forma, especiais, pois

4 O empate era um movimento organizado pelos próprios seringueiros para impedir a destruição tanto da fauna como da flora. [Melhorar esta nota, descrever melhor como se dava] 
a cada relato exposto é possível compreender o universo feminino com um olhar direcionado às suas experiências e anseios no mais íntimo de cada momento experimentado.

A pesquisa feita por meio de relatos de situações vivas na memória de determinadas pessoas traz à tona uma diversidade de testemunhos e experiências compreensíveis no âmbito social. A fala, o desabafo de algo de vivido de forma marcante, transforma-se em um documento crível para ser analisado e estudado. A busca por tal documento requer cuidado e organização.

Certamente, o apelo ao oral e audiovisual deve ser conduzido com o rigor e o cuidado que todo estudo histórico requer, buscando, inclusive, a precisão máxima ao organizar informações. Articular narrativas coletadas com outros materiais disponíveis sobre as experiências que abordam não corresponde a "corrigir" o que um narrador falou sobre suas experiências nem a transformar seu pensamento em mera fonte "complementar" (SILVA, 2003:75).

A entrevista é um método que busca com intensidade as respostas para indagações a respeito de determinados fatos. Faz-se crescente a necessidade de informações que não são encontradas em livros ou mesmo documentos escritos. Através de tais entrevistas, esclarecimentos, relatos e experiências únicas que são, de fato, história oral, a história falada, contada por quem a viveu. Nas palavras de Portelli (1981) "[a] história oral não tem sujeito unificado", o que permite que existam vários de pontos de vista sob as perspectivas do narrador.

A história oral, assim como a tradição, traz à tona a reflexão de que a memória e o testemunho vivo contribuem para o regate de muitos acontecimentos importantes ou mesmo marcantes para a sociedade atual, favorecendo o esclarecimento e, de certa forma, o reconhecimento de pessoas e fatos que, para muitos estudiosos da história e da sociedade hodierna, permanecem obscuros.

Para as entrevistas, foram selecionadas mulheres que trabalharam como seringueiras em meados dos anos 1960 e 1980 em seringais do Acre, e que se fizeram presente em momentos diferenciados nestes 
locais, trabalhando, além da seringa, na roça, em plantações e coIheitas, criando animais domésticos, bem como em muitas outras funções, incluindo o trabalho de donas de casa, cuidado com os maridos e a criação e educação de filhos.

Uma senhora narrou que trabalhou por 47 anos em seringais relatou que saiu do último seringal no interior de Xapuri para morar na cidade há somente cinco anos, porque um fazendeiro os expulsou de lá sem nenhum direito. Seus filhos mais velhos, que já moravam na cidade, ajudaram-na, pois a idade avançada a impede de trabalhar.

Em uma outra entrevista uma senhora filha de seringueiros relata com pesar a história da mãe já falecida, mas que foi uma exímia seringueira, a qual veio para a Amazônia com o esposo e três filhos no início dos 1940. No navio, durante a longa viagem, o marido e dois de seus filhos morreram.

Outro fator preocupante para as mulheres era a falta de estudo, tão necessário para os filhos, como explicou outra mulher seringueira que nasceu e cresceu nesse período. Afirmou a mesma que, sendo filha de seringueiros, a vida era muito dura, motivo pelo qual casou-se muito jovem. Contudo, teve o privilégio de ser ensinada pela mãe na "carta de ABC". A mãe, muito religiosa, ensinava os filhos e os empregados do seringal a ler e também a fazer orações de agradecimento a Deus, festejando todos os dias santos da Igreja Católica.

Para uma outra senhora trabalhadora, que em seu distinto relato deixou em evidência sua preocupação com a saúde, hoje resta uma situação delicada, já que trabalhou muito, desde a mais tenra idade, carregando peso excessivo em seu frágil e pequeno corpo infantil. As consequências deste árduo trabalho refletem-se sobremaneira em seu estado atual, e a mesma busca, através de tratamentos médicos, meios que possam ajudá-la a manter-se mais saudável.

Em meio a algumas entrevistas ficou perceptível a satisfação de algumas mulheres em falar e, ao mesmo tempo, para boa parte delas, a surpresa pelo fato de ter alguém interessada em ouvir suas memórias, suas histórias de vida. Na residência de uma senhora que trabalhou durante quatro anos cortando seringa e colhendo o látex, uma das 
filhas disse em tom de brincadeira: "[e]la adora falar desse tempo e nem sempre encontra quem queira ouvir". Quando indagada sobre as maiores dificuldades enfrentadas no período em que trabalhou no seringal, ela falou que eram muitas. Em sua narrativa, quando se referiu ao pai e à valorização ou ao reconhecimento que deveria ter recebido pelo trabalho exercido no seringal, expressou profunda tristeza.

Através dessas pesquisas é possível verificar a espécie de trabalho que se propagou não só na região norte, mas também em outras regiões brasileiras, um trabalho árduo, podendo ser classificado como "trabalho-escravo" ao qual se refere Slennes (2000) quando retrata a família negra escravizada no Brasil. No interior dos seringais, o trabaIho árduo e, de certa forma, "escravo", também foi forjando a família que ia aos poucos se formando e adquirindo espaço nos barracões.

O compromisso do historiador com a realidade social é de suma importância para a reflexão histórica sobre memória. Segundo Khoury (2000), é um conhecimento sobre a experiência humana para reconhecer-se como sujeito social.

A abordagem registra o relato, expõe experiência de vida, de lutas e principalmente de envolvimento com a sociedade em que se convive. Compreendendo o contexto em que viveram e ainda vivem as mulheres que trabalham em seringais é notório observar que a maioria delas permanece sob uma realidade de vida completamente recheada por lutas, necessidade de realizações e reconhecimento de seu valor.

A compreensão de todo o universo do trabalho feminino em seringais do Estado do Acre e a essência de suas lutas, assim como as inúmeras batalhas travadas dia a dia em busca de sustento para si e para seus familiares, tornou-se bastante explícita quando analisados os relatos dos meios utilizados por essas mulheres para desenvolver seus talentos no dificultoso trabalho.

As muitas funções absorvidas, adquiridas e cumpridas com êxito por mulheres destemidas e inteiramente convictas de seus papéis em meio à sociedade e, principalmente, no seio de suas famílias, fazem parte de uma imensidão de deveres e obrigações que as tornam capazes não só de assumir posições de responsabilidade e lideran- 
ça, como também de posicionarem-se frente a inúmeras questões políticas e sociais.

O trabalho da mulher Acreana, seja cortando seringa, seja plantando, seja ajudando o esposo para sustentar a família ou mesmo assumindo a posição de responsável pelo sustento do lar, ainda é silencioso. O reconhecimento de tudo isso perdura buscando dias melhores, contudo, um número razoável de mulheres apresenta uma espécie de conformação com o fato, como se o mesmo, no momento, já não tivesse tanta importância.

\section{REFERÊNCIAS}

ALBERTI, Verena; PINSKI, Carla Bassanezi; BACELAR, Carlos; GRESPON, Jorge; NAPOLITANO, Marcos; JANOTTI, Maria de Lourdes; FUNARI, Pedro Paulo; LUCA, Tania Regina de; BORGES, Vavy Pacheco Fontes Históricas $2^{a}$. Edição, Editora Contexto.

ALBUQUERQUE, Gerson Rodrigues de. Trabalhadores do Muru, o rio das garças. Rio Branco: EDUFAC, , 2005 (Série Dissertações e Teses 8)

AMADO, Janaína e Marieta de Moraes Ferreira (Organizadoras) Usos e Abusos da História Oral. $3^{a}$. Edição, Editora Fundação Getúlio Vargas, Rio de Janeiro, 2000.

BENCHIMOL, Samuel. Amazônia: um pouco - antes e além - depois. Manaus: Editora Umberto Calderaro, 1977.

BRUSCHINI, Cristina - Trabalho Feminino: Trajetória de um tema, Perspectivas para o futuro. Universidade Federal do Rio de Janeiro Escola de Comunicação - CIEC / Centro Interdisciplinar Estudos Contemporâneos. Rio de Janeiro. 1994

DELGADO, Maria Berenice. Mulheres na CUT: um novo olhar sobre o sindicalismo.In: BORBA, Ângela; FARIA, Nalu; GODINHO, Tatau (Orgs.). Mulher e política; gênero e feminismo no Partido dos TrabaIhadores. São Paulo: Fundação Perseu Abramo, 1998. 
FURTADO, Celso. Formação Econômica do Brasil. 10ª . Edição. Companhia Editora Nacional. São Paulo - SP, 1970.

MARTINELLO, Pedro. A "batalha da borracha" na segunda guerra mundial e suas consequências para o vale Amazônico. Série "C" Estudos e Pesquisas. RioBranco: EDUFAC, Universidade Federal do Acre, 1988.

MIRANDA, Gabriela Alves - Saúde e Doença na Batalha da Borracha - o Serviço Especial de Mobilização dos Trabalhadores para a Amazônia (SEMTA) (1942-1944).

NASCIMENTO, Maria das Graças. O Espaço Ribeirinho: migrações nordestinas para os seringais da Amazônia. Dissertação de Mestrado, FFLCH-DG/USP, São Paulo, 1996.

PORTELLI, Alessandro: O que faz a história oral diferente . In: PROJETO HISTÓRIA: Revista do Programa de Estudos Pós-graduados em História e do Departamento de História da PUC-SP (Pontifícia Universidade Católica de São Paulo). São Paulo, SP, 1981.

PRADO, Maria Lígia Coelho; CAPELATO,Maria Helena Rolim. A borracha na economia brasileira da primeira República. In História Geral da Civilização Brasileira, Boris Fausto (org.), tomo III - O Brasil republicano, vol. 1 - Estrutura de poder e economia (1889-1930), 4a ed., São Paulo, Difel, 1985.

RUA, Maria das Graças; ABRAMOVAY, Miriam Companheiras de luta ou coordenadoras de panelas"? As relações do gênero nos assentamentos rurais. UNESCO, Brasília, 2000.

Revista de Estudos Femininos vol.10 no. 1 Florianópolis Jan. 2002 Mulheres e sustentabilidade na Amazônia

SADER, Éder. Quando novos personagens entraram em casa: experiências, falas e lutas dos trabalhadores da Grande São Paulo, 1970/80. $1^{\text {a }}$. edição. Editora Paz e Terra S/A. Rio de Janeiro, 1988.

SECRETO, Maria Verônica A ocupação dos "espaços vazios" no governo Vargas: do "Discurso do rio Amazonas" à saga dos soldados 
da borracha. In: Revista de Estudos Históricos, Rio de Janeiro, no. 40 - 2007.

Curtidas na saudade: Mulheres de "soldados da borracha" queixavam-se da vida dura nos alojamentos e reivindicavam assistência do governo.

SILVA, Marcos A. da. História: o prazer em ensino e pesquisa. $1^{a}$. Reimpressão, Editora Brasiliense, São Paulo - SP, 2003

SILVA, Maria de Andrade "A borracha passada na História"(Os Soldados da Borracha durante a Segunda Guerra) -Monografia apresentada como requisito parcial para obtenção do grau de Bacharel em História, na disciplina de Orientação do Trabalho Monográfico, pela Universidade do Estado de Santa Catarina, sob a orientação da professora Doutora Marlene de Fáveri. Universidade do Estado de Santa Catarina Florianópolis, 2005.

SILVEIRA, Valéria Barbosa Ferreira.Amazônia Acreana: Palco Para a Leitura de Folhetos (Universidade Federal do Acre).

SIMONIAN, Lígia T. C. Mulheres da Floresta Amazônica entre o trabaIho e a cultura Belém: UFPA/NAEA, 2001.

SOUZA, Carlos Albert Alves de Aquirianas: mulheres da floresta na história do Acre - Instituto de Pesquisa, Ensino e Estudos das Culturas Amazônicas - Rio Branco, 2010.

SOUZA, Gisele Elaine de Araújo Batista; France Maria Gontijo CoeIho; Marcelo Miná Dias. - Movimentos Sociais dos Seringueiros e a Reserva Chico Mendes: a cada conquista, persiste a necessidade das lutas.Grupo de Pesquisa: Políticas Sociais para o Campo. Universidade Federal de Viçosa - UFV, Viçosa - MG.

VIEIRA, Maria do Pilar de Araújo, Maria do Rosário da Cunha Peixoto, Yara Mária Aun Khoury. A Pesquisa em História. $4^{\mathrm{a}}$. edição, $5^{\mathrm{a}}$. reimpressão. Editora Ática, São Paulo - SP, 2005. 